\title{
Andrew King, Kathryn Almack, \& Rebecca L. Jones (eds.) (2019). Intersections of Ageing, Gender and Sexualities: Multidisciplinary International Perspectives. Bristol: Policy Press 264 pp. ISBN 978-1447343370 (paperback)
}

\author{
Reviewed by Maria Cheshire-AlleN*
}

This collection is a welcome newcomer to the study of intersectionality, working on several levels, and its appeal lies in its innovative application of theory, containing contributions from a wide range of disciplines, including sociology, gerontology, psychology and policy studies. The collection does not shy from the challenge of binding the disparate disciplinary approaches into a cohesive collection. Recognisable from the outset is a clear connecting theme of an appeal to, and demonstration of the potential of intersectional theory to ideas of social justice and challenge to new types of inequalities in later life.

Using intersectional analysis, the book comprises of 14 chapters that offer empirical as well as theoretical cotemporary accounts. The chapters are stratified according to four broad themes: part 1 - theoretical interpolations, part 2 - representations, part 3 - dis/empowerments and

${ }^{*}$ Maria Cheshire-Allen, Centre for Ageing and Dementia Research, Swansea University, Wales, UK. 
International Journal of Ageing and Later Life

part 4 - health and wellbeing. In chapter 2, Toni Calasanti provides the necessary theoretical anchor points for subsequent chapters by detailing precisely what an intersectional analysis and approach entails and a presentation of these ideas to spousal caregiving. Asserting first that an intersectional analysis is concerned with systems of social inequalities that are explored through a lens that recognises more than one single axis of social division (gender, race and age). Second, an intersectional approach relates groups theoretically identifying the institutionalised activities that maintain inequality. This is an important point that exemplifies the distinctiveness and critical purchase that an intersectional approach can offer, particularly, to those who interested in theories of social justice and social policy. Following from this, Yvette Taylor's though provoking subsequent chapter 3 on queer families, queer care and queer academia applies the concepts introduced in the previous chapter in a distinctive way through her analysis of time. Taylor demonstrates the saliency of normative gendered trajectories that serve to demarcate "normal times" on which to have children for example and introduces through an intersectional analysis the idea of a "time bomb" where these gendered and sexualised expectations are disrupted.

Part 2 of the book is focused on the theme of "representations" and draws upon textual sources including Virgina Woolf, Doris Lessing and Lynn Segal to discuss characterisations of female ageing with a particular focus on the menopause. Chapter 6 by Maricel Oro Piqueras provides an interesting account of how sexuality and ageing have been culturally presented, particularly in relation to female ageing. Kinneret Laha and Karen Hvudtfeldt's chapter brings a contemporary angle to this collection by drawing upon sources of data based on online web columns and magazine articles to analyse ageist stigmas in relation to midlife motherhood in Denmark and Israel.

The book's aim to reflect upon discussions and data drawing from an international perspective is provided in part 3 of the book, which successfully demonstrates the currency of an intersectional analysis that can travel beyond the global north and for this reason, the insights and findings presented are particularly illuminating. A fascinating study of Iranian Muslim menopausal women is provided in Chapter 9 by Elham Amini, who offers rich methodological insight reflecting on, as she does 
her role as a researcher of older Iranian women and her identity as a younger woman educated in a western country, as she notes, intersectionality theory, which emphasises the intersection of identities and addresses the power relationships present during the interviews (p. 141). The novel and innovative application of intersectional theory is again presented in preceding chapters by Finn Reygan and Jamil Khan, whose study into care service provision for lesbian, gay, bisexual, transgender and intersex (LGBTI) elders in South Africa is noted by the authors to be the first writings from South Africa on this topic. Part 3 concludes with a study based on original research conducted in a Spanish long-term care facility; the authors reflect on how residents' sexual expressions are limited or problematised by both staff and co-residents that can be understood through an intersection analysis of gender and sexuality.

Part 4 titled "health and wellbeing" begins with Mark Hughes's study of health and wellbeing of older lesbians, gay men and bisexual people. This chapter summarises findings based on quantitative methods and stands alone as the only chapter in the collection to report exclusively on quantitative data. Absent from this collection thus far is studies focused on the male experience. Chapter 13 and subsequent chapters in this section address this imbalance. A mixed method analysis of how medical experts in Italy dealing with male patients sexual health problems is provided by Raffaella Ferrero Camoletto, whose study findings show how medical professionals reproduce and renegotiate what they perceive as "respectable sexuality" and "mature masculinity." This chapter is particularly compelling as it demonstrates how an intersectional analysis can reveal damaging discourses (reinforced by medical opinion and professionals) that, as the authors note, leave older ageing men living up to the ideal of mature masculinity and leave little room for alternative accounts of male sexual ageing. The final chapter of this collection is again focused on the male experience and provided by Julie Fish who explores the gay and bisexual men's narratives of prostate cancer from an intersectional perspective concluding with a series of policy implications which are particularly helpful in grounding the findings within the policy context in the UK.

This is a comprehensive and detailed book, and it makes a distinctive contribution to the field; although some of the authors (highlighted here) do offer policy implications based on the study findings, this is not a 
International Journal of Ageing and Later Life

collection that can speak readily to practitioners or policy makers. This is not surprising, given the infancy of some of the theoretical anchor points that the book elucidates. Sparking future debate and discussion amongst a wide audience is the stated aim of the book, and this book achieves this through a lively and disparate collection providing important insights grounded in empirical and critical theory. This book's contribution can be recognised for its novel theoretical and methodological insights, pushing theoretical and disciplinary boundaries, and for this reason, the book stands as an essential and key text for all those interested in ageing and social justice issues. 